\title{
Influence of cyclodextrins on the photostability of selected drug molecules in solution and the solid-state
}

\author{
B. D. Glass, ${ }^{1, \dagger}$ M. E. Brown, ${ }^{2}$ S. Daya, ${ }^{1}$ M. S. Worthington, ${ }^{3}$ P. Drummond, ${ }^{1}$ \\ E. Antunes, ${ }^{2}$ M. Lebete, ${ }^{1}$ S. Anoopkumar-Dukie, ${ }^{1}$ and D. Maharaj ${ }^{1}$ \\ ${ }^{1}$ Faculty of Pharmacy, Rhodes University, PO Box 94, Grahamstown.6140 South Africa \\ 2 Department of Chemistry, Rhodes University, PO Box 94, Grahamstown.6140 South Africa \\ ${ }^{3}$ Aspen-Pharmacare, PO Box 4002, Korsten.6014. South Africa
}

\begin{abstract}
The photostability of selected drug molecules, including furosemide, prochlorperazine, diclofenac, piroxicam, midazolam and nifedipine was studied, the kinetics of photodegradation, identification of the photodegradants investigated and mechanisms of photodegradation proposed. Selected cyclodextrins altered the photodegradation profiles of diclofenac, piroxicam, midazolam and nifedipine by either accelerating or retarding the rate of photodegradation and generating novel photodegradants.
\end{abstract}

\section{INTRODUCTION}

Knowledge of the photostability of drug molecules and drug formulations has developed into an important research area. There is a need to evaluate and provide information on handling, packaging, labeling, and therapeutic and adverse aspects of drug delivery systems. Photodecomposition of a drug may result in a loss of potency of the product and the development of adverse effects may be attributable to the formation of photodegradants during storage or administration of the drug product. An increasing number of drugs are being found to undergo photodegradation, with the European Pharmacopoeia prescribing, "protect from light" for at least 250 drug molecules and excipients [1].

Because of the growing interest in cyclodextrins and their ability to improve both the solubility and stability of drug molecules, with resulting enhanced bioavailability, the effect of inclusion complexation with cyclodextrins and cyclodextrin derivatives on the photostability of selected drug molecules has been investigated. The photochemistry and photophysics within the cyclodextrin cavity involves features that are quite distinct from uncomplexed substances, because the interior of the cavity constitutes an isolated environment where the included species is usually present as a single molecule. The photochemistry is therefore generally restricted to intramolecular events, except in cases of double or multiple occupancy [2]. Cyclodextrin inclusion complexation may increase, decrease, or have no effect on the rate of photodegradation of the drug and may even change the nature of the photodegradants. It is thus important to study the effects of this range of excipients.

In addition to a study on the photostability of these

† E-mail: B.Glass@ru.ac.za selected drug molecules, this paper will relate structural features of these drug molecules to both activity and stability, with a view to identifying common structural features, which contribute to the photo-instability and the resulting adverse effects of drug molecules.

\section{MATERIALS AND METHODS}

2.1. Materials. Furosemide, prochlorperazine, diclofenac, piroxicam, midazolam and nifedipine, and selected cyclodextrins were donated by AspenPharmacare Ltd, Port Elizabeth, South Africa and were used without further purification. Water was purified on a Milli-Q (Millipore) device, methanol (HPLC) grade used for HPLC was from Romil Ltd, Cambridge and all other chemicals used were at least of analytical grade.

2.2. Irradiations. For kinetic and analytical studies solutions of furosemide, prochlorperazine and diclofenac were irradiated with a medium pressure $400 \mathrm{~W}$ mercury lamp in a quartz photo-reactor for various time-periods, midazolam in USP type 1 glass ampoules in an Hereaus Suntest CPS+ at $550 \mathrm{~W} / \mathrm{m}^{2}$ for 12 hours using an ID 65 filter and solid nifedipine through window-filtered sunlight. These irradiations were carried out in the presence and absence of selected cyclodextrins.

2.3. Analytical methods. Irradiated solutions and solids were analysed by HPLC on $\mathrm{C}_{18} 250 \times 4 \mathrm{~mm}$ columns using methods, which had been developed and validated in terms of the USP parameters while photoproducts were identified using LC-MS studies.

\section{RESULTS AND DISCUSSION}

3.1. Furosemide,prochlorperazine and diclofenac. Many drugs causing adverse photosensitivity effects 
contain chlorine atoms as substituents, with the photolabile nature of chlorine being shown in many chloroaromatic compounds [3]. The photolysis of furosemide 1 in oxygen-free methanol is represented in Scheme 1 [4], illustrating the major pathway of degradation to be reduction and substitution, a pattern observed for other simple aromatic compounds with the mechanism as proposed by Soumillion and De Wolf [5] shown in Scheme 2.<smiles>NS(=O)(=O)c1cc(C(=O)O)c(NCc2ccco2)cc1Cl</smiles>
Furosemide

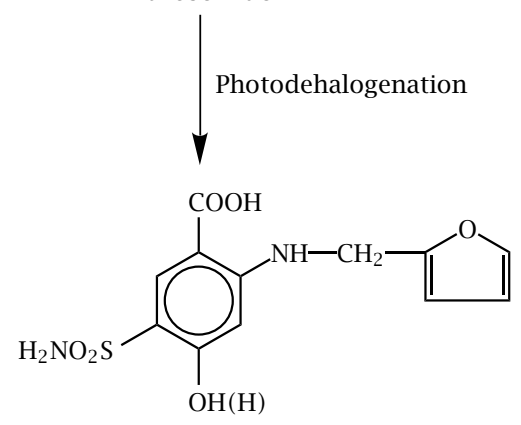

Photosubstitution(Photoreduction)

Scheme 1. Photodegradation of furosemide in oxygen-free methanol.

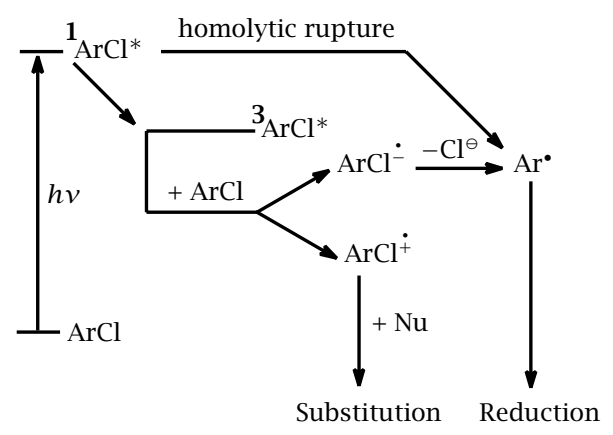

Scheme 2. General pathway for the photoreduction and photosubstitution of chloroaromatic compounds.

The photodegradation of prochlorperazine 2 and other structurally related propyl piperazinesubstituted phenothiazines with improved potency over the prototype chlorpromazine (Scheme 3) in aqueous solution, displayed first-order kinetics with the pseudo first-order rate constants indicating that the chloro-derivatives, specifically perphenazine 3 to be less stable than the trifluoromethyl derivatives and although Pawelczyk et al. have confirmed these

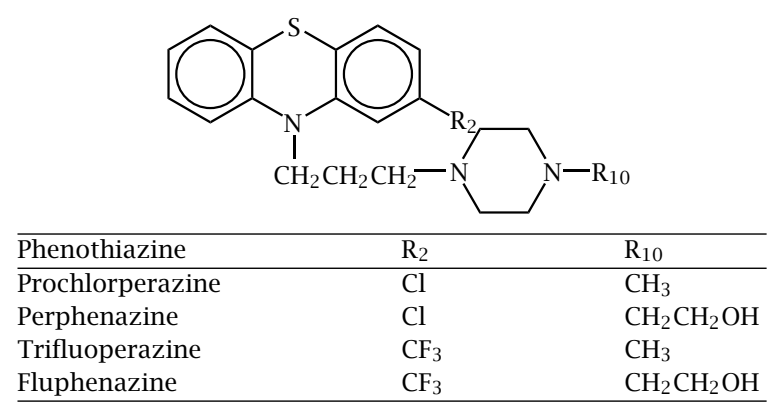

Scheme 3. Structures of piperazine-substituted phenothiazine derivatives.

results with both thermal and photolytic degradation studies on prochlorperazine and trifluoperazine 4, this study extends their considerations of the effect of the $R_{2}$ substituent to include the $R_{10}$ substituent [6-8]. Results indicate the order of stability to be trifluoperazine $>$ fluphenazine $>$ prochlorperazine $>$ perphenazine confirming the $\mathrm{R}_{2}$ and not the $\mathrm{R}_{10}$ to be the major determinant of stability.

LC-MS studies showed sulphoxidation to be a common route of degradation for the four piperazinesubstituted derivatives on exposure to light, while evidence of dehalogenation and subsequent photoreduction and photosubstitution for the chlorine-containing derivatives, (Scheme 4, Photodegradation pathway of prochlorperazine) sulphonation and dealkylation are amongst the other degradation pathways observed in the photostudies.<smiles>CN1CCN(CCn2c3ccccc3sc3ccc(O)cc3n2CCN2CCN(C)CC2)CC1</smiles>

Scheme 4. Photodegradation pathway of prochlorperazine.

Diclofenac 5 has also been reported to cause phototoxicity effects in patients due to a free radical photodechlorination process [9]. The photodegradation of diclofenac shown in Scheme 5, in aqueous solution involved the loss of $\mathrm{HCl}$ to form the chlorocarbazole 6 with subsequent loss of the second chlorine on further irradiation. This photodechlorination results in the formation of the photosubstituted (hydroxy carbazole) 7 and the photo-reduced product 8 . 
<smiles>CC(C)CCc1cccc2c1[nH]c1c(Cl)cccc12</smiles>

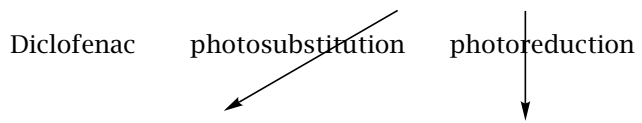<smiles>O=C(O)Cc1cccc2c1[nH]c1c(O)cccc12</smiles><smiles>O=C(O)Cc1cccc2c1[nH]c1ccccc12</smiles>

Scheme 5. Photodegradation pathway of diclofenac.

Effect of 2-hydroxyporpyl- $\beta$-cyclodextrin (2 HP- $\beta$ CD) on the photostability of diclofenac is illustrated in Figure 1 where the drug appears to be more stable then the complex for $\mathrm{T}<30$ minutes and thereafter degrades rapidly and the complex appears to be more stable. This enhanced stability may be explained by reference to the modeling of the diclofenac $/ \beta$-CD complex [10]. Because of the angled conformation of the two aromatic rings, partial inclusion of the part with the two chlorine atoms due to its hydrophobicity, compared, to that of the polar carboxy group, which protrudes from the $\mathrm{CD}$ structure, occurs, thus protecting the site of diclofenac photodegradation. 2 HP- $\beta$-CD catalyses the reduction of the chlorocarbazole derivative via an unknown intermediate and suppresses the formation of the hydroxycarbazole derivative. The rate of formation of the reduced carbazole derivative is greatly accelerated and $2 \mathrm{HP}-\beta$-CD also facilitates the formation of dimers and polymers due to the photochemistry and the photophysics of the cavity involving features, which are distinct from that of the uncomplexed drug and stabilizing free radicals.

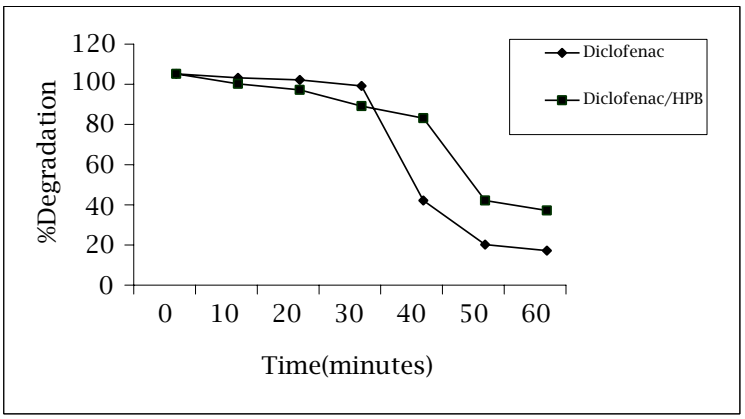

Figure 1. \% Degradation of diclofenac in the absence and presence of 2-hydroxypropyl- $\beta$-cyclodextrin.
3.2. Piroxicam. Although the photodegradation of piroxicam 9 in dichloromethane has been reported [11], Kochevar et al. [12] have found that phototoxicity in animals is due to a metabolite of piroxicam and that photosensitivity in patients is due to the preferential synthesis of this metabolite. Ljunggren [13] thus suggested that instead of investigating the photobiology of piroxicam itself, attention should be focused on its photoproducts.

Four photodegradation products (Scheme 6) were isolated from a methanolic solution of photolysed piroxicam, using flash chromatography in combination with semi-preparative HPLC. Gas chromatography was used to assess both the purity of each photoproduct, as well as the relative amounts formed: namely $60.6 \%$, 10, 6.3\%, 11, 11.0\%, 12 and 20.3\%, 13. The photoproduct structures were assigned by ${ }^{1} \mathrm{H}-\mathrm{NMR},{ }^{13} \mathrm{C}-\mathrm{NMR}$, IR and MS. In some instances, two-dimensional NMR spectroscopy was required for assignment of the chemical structure. 10, $\left(\mathrm{C}_{8} \mathrm{H}_{7} \mathrm{NO}_{3} \mathrm{~S}\right)$ and $12\left(\mathrm{C}_{8} \mathrm{H}_{8} \mathrm{~N}_{2} \mathrm{O}_{3}\right)$ were identified as 2-methyl-1, 2-benzisothiazol-3(2H)-one1,1-dioxide and N-(2-pyridyl)-methoxy-formyl-amide, respectively. It is postulated that their formation in methanol is due to incorporation of oxygen into piroxicam, with ring cleavage of the dioxetane intermediate and conversion of the resultant carboxylic acid into $\mathbf{1 0}$ and 12 via a transacylation reaction and a nucleophilic attack by the oxygen lone pair of electrons of methanol. Subsequent decarbonylation of $\mathbf{1 2}$ led to the formation of $11\left(\mathrm{C}_{7} \mathrm{H}_{8} \mathrm{~N}_{2} \mathrm{O}_{2}\right)$, identified as N-(2-pyridyl)-methoxyamide. The formation of $\mathbf{1 3}\left(\mathrm{C}_{8} \mathrm{H}_{9} \mathrm{~N}_{3} \mathrm{O}_{2}\right)$, identified as $\mathrm{N}$ methyl-N'-(2-pyridyl)-ethane-diamide, is postulated to occur as a result of cleavage of the sulphur-nitrogen bond in the carboxylic acid.

The photolytic degradation of piroxicam did not follow simple kinetics with a non-linear relationship being found for the plots of percentage piroxicam remaining versus irradiation time. It is thus proposed that the reaction scheme of piroxicam photodegradation is more complex than a simple bimolecular encounter, with secondary photodecomposition and autocatalytic processes compounding the kinetic complexity. Comparison of the photodegradation profiles obtained for piroxicam and piroxicam- $\beta$-cyclodextrin provided no indication that the $\beta$-cyclodextrin had any significant effect on the rate of piroxicam photodegradation. These results may be explained in terms of the proposed mode of inclusion complexation by Fronza et al. [14], (Figure 2) which shows that the site of photodegradation has been excluded from the cyclodextrin cavity.

3.3. Midazolam The photochemical decomposition of midazolam 14 has been investigated [15-17]. The photodegradation of midazolam in aqueous solution $\left(550 \mathrm{~W} / \mathrm{m}^{2}\right.$ for 12 hours in an Atlas SUNTEST CPS+, fitted with a Xenon lamp and a solar ID65 filter) 
<smiles>CN1Sc2ccccc2C(O)C1C(=O)Nc1ccccn1</smiles>

Piroxicam

$$
\overrightarrow{\mathrm{h} v / \mathrm{O}_{2}}
$$<smiles>CCC</smiles><smiles>CN(Sc1ccccc1C(=O)O)C(=O)C(=O)Nc1ccccn1</smiles><smiles>CNC(=O)C(=O)Nc1ccccn1</smiles>
13<smiles>Cn1oc2ccccc2c1=O</smiles><smiles>CN1Sc2ccccc2C2(O)OC(=O)N(C)C12O</smiles><smiles>COC(=O)C(=O)Nc1ccccn1</smiles><smiles>COC(=O)Nc1ccccn1</smiles>

Scheme 6. Photodegradation pathway of piroxicam.

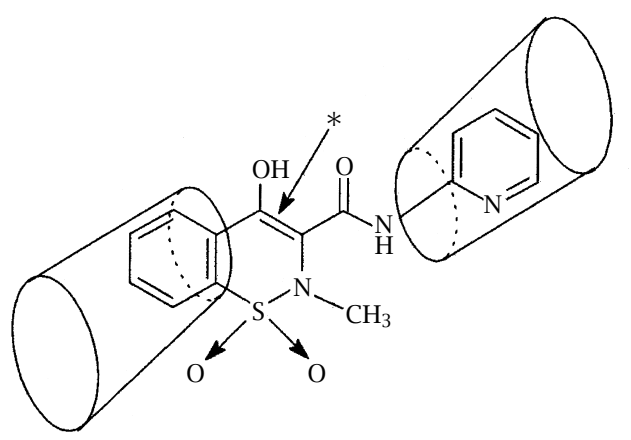

Figure 2. Proposed model for the inclusion of piroxicam into $\beta$-cyclodextrin.

showed similar behaviour in the presence and absence of randomly-methylated- $\beta$-cyclodextrin (RAMEB), with an indication of slightly decreased photostability in the presence of RAMEB. In both instances, two degradants, labeled A, 15 and B, 16 were noted, while in the pres- ence of RAMEB, a third degradants, C, 17 is also evident. In the absence of absolute amounts, the curves for these degradants have been scaled to fractions, $\alpha$ (alpha) of the maximum values reached. (Figures 3 and 4 )

In Figure 3, the three $(\alpha, \mathrm{t})$ curves for the disappearance of midazolam without RAMEB and the formation of degradants coincide until about 25\% degradation. In the latter stages, the curves for the degradants lie above that for the drug, but are similar to each other. The formation of the degradants A and B can be represented by equation (1).<smiles>[M]C([AlH])I</smiles>

where $\mathrm{M}$ is midazolam, $k_{1}$ and $k_{2}$ are the rate constants for the formation of $\mathrm{A}$ and $\mathrm{B}$, respectively. The initial stages of the degradation are acceleratory which suggests an autocatalytic effect of the degradants on the rate of degradation of the drug. In Figure 4, the curve 


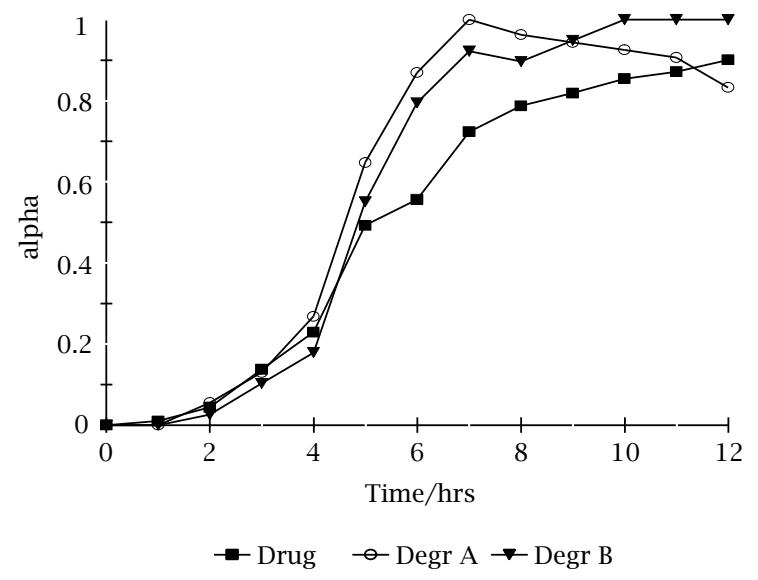

Figure 3. Curves for the disappearance of midazolam in the absence of RAMEB and the formation of degradants $A$ and $B$.

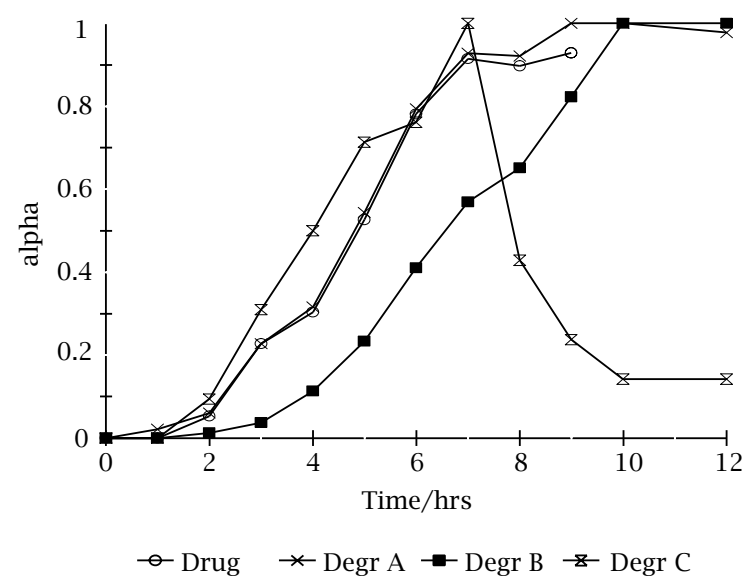

Figure 4. Curves for the disappearance of midazolam and the formation of degradants $A, B$ and $C$ in the presence of RAMEB.

for the production of degradant A is very similar to that for the degradation of the drug, with the production of the third degradant $C$, reaching a maximum after about $7 \mathrm{hrs}$, which corresponds to about $90 \%$ degradation of the drug. The amount of $\mathrm{C}$ then decreases over about $3 \mathrm{hrs}$ to $15 \%$ of its maximum value. At this total time of $10 \mathrm{hrs}$, the amount of degradant B reaches a maximum suggesting

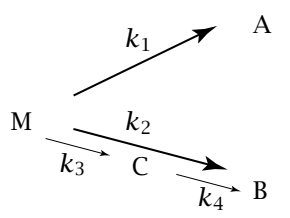

where $k_{3}$ and $k_{4}$ are the rate constants for the conversion of $\mathrm{M}$ to $\mathrm{C}$ and $\mathrm{C}$ to $\mathrm{B}$ respectively. Scheme 7 illustrates the formation of degradants $\mathrm{A}, \mathrm{B}$ and $\mathrm{C}$.<smiles>Cc1ncc2n1-c1ccc(Cl)cc1C(c1ccccc1F)=NC2</smiles><smiles>O=C1CN=C(c2ccccc2F)c2cc(Cl)ccc2N1</smiles>

Midazolam<smiles>C/C(=N\CC=O)N1c2ccc(Cl)cc2C(c2ccccc2F)=NC1C</smiles>

15

Scheme 7. Photodegradation pathway of midazolam.

Photodegradation of midazolam to degradant A follows opening of the imidazole ring with subsequent substitution to form the benzodiazepinone. As reported by Andersin et al. [16], degradant B is identified as 6-chloro-2-methyl-4-(2'-fluorophenyl)quinazoline, 16 which precipitates in solutions of midazolam exposed to daylight. In this study, the precipitate appeared after 6 hours of exposure and as shown in Figure 3 , at this time the amount of $\mathbf{1 6}$ was approaching a maximum value. The proposed identification of $\mathbf{1 6}$ is consistent in that the compound is more hydrophobic than 15 explaining why $\mathbf{1 6}$ precipitated out of solution as the concentration increased. The absence of a precipitate in the RAMEB solutions, in spite of evidence of the presence of $\mathbf{1 6}$ as a major degradation product, can be explained by the ability of RAMEB to improve the solubility of hydrophobic compounds. RAMEB caused the formation of $\mathbf{1 7}$, following the addition of a more polar molecule such as oxygen resulting in a higher molecular mass. From the kinetic studies it was postulated that $\mathbf{1 7}$ is an intermediate in the formation of $\mathbf{1 6}$ implying that $\mathbf{1 7}$ has the structure of $\mathbf{1 6}$ as part of its structure.

3.4. Nifedipine. Nifedipine 18 , being a dihydropyridine derivative, is extremely photolabile [18-20] 
and decomposes in daylight to 2,6-dimethyl-(2nitrosophenyl)-3,5-pyridine dicarboxylic acid dimethyl ester (nitrosopyridine derivative), $\mathbf{1 9}$ and in UV light to the oxidation product, 2,6-dimethyl-4-(2nitrophenyl)-3,5-pyridine dicarboxylic acid dimethyl ester (nitropyridine derivative) 20.

The solid-state photostability of powdered nifedipine-cyclodextrin binary systems were assessed in order to establish whether selected cyclodextrins could stabilize nifedipine upon exposure to light. The kneaded mixtures of nifedipine with $\beta$-CD, $\gamma$-CD, 2 HP- $\beta$-CD, RM- $\beta$-CD and 2,6-dimethyl- $\beta$-cyclodextrin $(\mathrm{DM}-\beta-\mathrm{CD})$ were prepared in 1:1 stoichiometric ratios using a suitable kneading method for industrial application and exposed to window-filtered sunlight together with their respective physical mixtures. The degree of photostabilization is expressed as the stability indicating ratio ( $k$ \{physical mixture $\} / k\{$ kneaded product\}). This approach permitted comparative photostudies to be performed over a number of months without seasonal fluctuations in light intensity dramatically affecting the general comparative stabilizing trend for a particular nifedipine-cyclodextrin binary system. The kneaded nifedipine-cyclodextrin binary systems degraded rapidly by first-order kinetics when exposed to morning daylight. Photodegradation halflives were generally less than 60 minutes irrespective of the nifedipine-cyclodextrin molar ratio, the cyclodextrin used, the method of preparation or the time of year during which the experiment was performed. A slight improvement in the nifedipine photostability was observed for the $\beta$-CD and $\gamma$-CD kneaded products prepared in 1:1 molar ratios. The photostability of nifedipine in these systems increased by a factor $\left(R_{\mathrm{SI}}\right)$ of 1.69 and 1.93 when kneaded with $\beta$-CD and $\gamma$-CD, respectively (Table 1 ) Kneading with $2 \mathrm{HP}-\beta-\mathrm{CD}$ produced a slight destabilizing effect relative to the control. The photodegradation half-life of nifedipine decreased from 43.6 minutes in the physical mixture to 34.7 minutes in the kneaded product. Neither a stabilizing nor destabilizing effect was observed for the $1: 1$ nifedipine: $\mathrm{RM}-\beta-\mathrm{CD}$ and nifedipine: $\mathrm{DM}-\beta-\mathrm{CD}$ kneaded products.

The impact of changing nifedipine-cyclodextrin stoichiometries on nifedipine photostability was investigated for the 2:1 and 1:2 nifedipine: $\gamma$-CD and nifedipine: RM- $\beta$-CD kneaded products. The stability indicating ratios for the nifedipine: $\gamma$-CD binary systems increased in the order, $1: 2>1: 1>2: 1$, indicating that the stabilizing effect of $\gamma$-CD in the kneaded product relative to the physical mixture, increased as the cyclodextrin content increased. The RM- $\beta$-CD kneaded product produced little nifedipine photostabilization when prepared in a 1:1 molar ratio and changing the stoichiometry to $1: 2$ and 2:1 provided no additional stabilization.

The colour changes observed for the $\beta$-CD and
Table 1 . Stability indicating ratios $\left(R_{\mathrm{SI}}\right)$ for nifedipinecyclodextrin binary systems.

\begin{tabular}{lll}
\hline Description & Molar ratio & $R_{\mathrm{SI}}$ \\
\hline Nifedipine: $\gamma$-CD kneaded product & $1: 2$ & 2.28 \\
Nifedipine: $\gamma$-CD kneaded product & $1: 1$ & 1.93 \\
Nifedipine: $\gamma$-CD kneaded product & $2: 1$ & 1.81 \\
Nifedipine: $\beta$-CD kneaded product & $1: 1$ & 1.69 \\
Nifedipine:RM- $\beta$-CD kneaded product & $2: 1$ & 1.12 \\
Nifedipine:RM- $\beta$-CD kneaded product & $1: 2$ & 1.05 \\
Nifedipine:RM- $\beta$-CD kneaded product & $1: 1$ & 0.96 \\
Nifedipine:2 HP- $\beta$-CD kneaded product & $1: 1$ & 0.80 \\
Nifedipine:DM- $\beta$-CD kneaded product & $1: 1$ & 1.09 \\
\hline
\end{tabular}

$\gamma$-CD kneaded products could provide an explanation for their ability to weakly stabilize nifedipine. The surface colour of the 2 HP- $\beta$-CD, RM- $\beta$-CD and DM- $\beta$-CD kneaded products and their relative physical mixtures changed from bright yellow to dark yellow upon exposure to light. Matsuda et al. [21] observed similar colour changes when exposing nifedipine tablets to light and suggested that a relationship may exist between nifedipine photodegradation and the extent of colour darkening. The $\beta$-CD and $\gamma$-CD kneaded products on the other hand, assumed a pale yellow colour and by the end of the exposure were creamy-white in appearance. The photostabilization observed in the $\beta$ $\mathrm{CD}$ and $\gamma$-CD kneaded products could therefore be attributed to the opacity changes, which occurred during exposure. The extent of the light penetration into solid powder beds is known to influence the rate of photodegradation [22]. Opacity changes observed in the $\beta$-CD and $\gamma$-CD kneaded products therefore reduced light transmission into the underlying material and decreased the rate of nifedipine photodegradation.

\section{CONCLUSIONS}

The photodegradation kinetics and degradation pathways investigated and mechanisms proposed have confirmed that there is a relationship between structural features and the photostability of these selected drug molecules. This is well illustrated in the chlorine containing drugs furosemide, prochlorperazine and diclofenac where these substituents do not only contribute to activity but also to the photostability and the potential for adverse effects in patients.

The presence of cyclodextrins in solution has accelerated (midazolam), decelerated (diclofenac) and not affected (piroxicam) the rate of photodegradation of these drug molecules. These differences may be attributed to the mode of inclusion complexation as to whether the site of degradation is included or not into the cavity of the cyclodextrin molecule.

The cyclodextrins examined in the nifedipine study were found to be ineffective as single-component pho- 
tostabilizers. After studying the photochemical decomposition of a series of 1,4-dihydropyridine ester derivatives, Muller and Albers [23], concluded that photostabilization in solution could not be achieved by complexation with 2 HP- $\beta$-CD. Photodegradation of the $1,4-$ dihydropyridine-ester derivative led to the formation of a nitrosopyridine photoproduct via intramolecular disproportionation involving the removal of the two 1,4-dihydropyridine protons together with oxygen. It had been postulated that photodegradation could be reduced as a result of intermolecular hydrogen bonding between the 2 HP- $\beta$-CD and the 1,4 protons of the dihydropyridine ring. The inability of $2 \mathrm{HP}-\beta$-CD to photostabilize the 1,4-dihydropyridine ester derivative was therefore attributed to a lack of intermolecular hydrogen bonding between 2 HP- $\beta$-CD and the 1,4dihydropyridine ester derivative [23]. Since nifedipine is structurally related to the 1,4-dihydropyridine ester derivatives, it could therefore be rationalized that the poor nifedipine photostabilization observed in the present study was as a result of a lack of hydrogen bonding of the nifedipine 1,4-dihydropyridine protons with the cyclodextrin host, either as a result of the host-guest binding mechanism not involving hydrogen bonding of these particular protons or weak inclusion complexation. The latter assumption is considered more feasible since low affinity between nifedipine and cyclodextrins examined in this study was confirmed in solution in phase solubility studies and in solid-state kneaded products by differential scanning calorimetry, infrared spectroscopy and X-ray powder diffractometry.

The different photoproducts of both diclofenac and midazolam occurring in the presence of the cyclodextrins may be attributed to the ability of these molecules to affect the photobehaviour of drug molecules [24]. This does however provide valuable information, which can be used in the ongoing process of the development and validation of stability-indicating methods of analysis for these drug molecules where cyclodextrins have been included in the formulations as excipients.

\section{ACKNOWLEDGEMENTS}

The authors wish to acknowledge the co-authors, Lawrence Penkler and Darryl Whittaker and the financial support of the University of Port Elizabeth, Rhodes University and Pharmacare-Lennon.

\section{References}

[1] H. H. Tonnesen, Photostability of Drugs and Drug Formulations, H. H. Tonnesen (ed.), Taylor and
Francis Ltd, London, 1996, pp. 1-7.

[2] S. P. Jones, D. J. W. Grant, J. Hadgraft, and G. Parr, Acta. Pharm. Technol. 30 (1984), 263.

[3] D. E. Moore and S. R. Tamat, J. Pharm. Pharmacol. 32 (1980), 172.

[4] D. E. Moore and V. Sithipitaks, J. Pharm. Pharmacol. 35 (1983), 489.

[5] J. P. Soumillion and B. De Wolf, J.C.S. Chem. Comm. (1981), 436.

[6] E. Pawelczyk and B. Marciniec, B. Polish Journal of Pharmacology and Pharmacy 29 (1977), 137.

[7] E. Pawelczyk and B. Marciniec, B. Polish Journal of Pharmacology and Pharmacy 29 (1977), 143.

[8] E. Pawelczyk, B. Marciniec, and B. Matlak, Polish Journal of Pharmacology and Pharmacy 27 (1975), 317.

[9] D. D. Moore, S. Roberts-Thomson, D. Zhen, and C. Duke, Photochemistry and Photobiology 52 (1990), 685.

[10] T. Backensfeld, B. W. Muller, and K. Kolter, Int. J. Pharm. 74 (1991), 85.

[11] M. A. Miranda, F. Vargas, and G. Serrano, J. Photochem. Photobiol. B: Biol. 8 (1991), 199.

[12] I. E. Kochevar, M. L. Morison, J. L. Lamm, D. J. Mc Auliffe, A. Western, and A. F. Hood, Arch. Dermatol. 122 (1986), 1283.

[13] B. Ljunggren, Photodermatol. 6 (1989), 151.

[14] G. Fronza, A. Mele, E. Redenti, and P. Ventura, J. Pharm. Sci. 8112 (1992), 1162.

[15] R. Selkamaa and S. Tammilehto, Int. J. Pharm. 49 (1989), 83.

[16] R. Andersin and S. Tammilehto, Int. J. Pharm. 56 (1989), 175.

[17] R. Andersin, J. Ovaskainen, and S. Kaltia, J. Pharm. Biomed. Anal. 122 (1994), 165.

[18] R. Testa, E. Dolfini, C. Reschiotto, C. Secchi, and P. A. Biondi, Il Farmaco 34 (1979), 463.

[19] P. Jakobsen, O. Lederballe Pedersen, and E. J. Mikkelsen, J. Chromatogr. 162 (1979), 81.

[20] P. Pietta, A. Rava, and P. J. Biondi, J. Chromatogr. 310 (1981), 219.

[21] Y. Matsuda, R. Teraoka, and I. Sugimoto 54 (1989), 211.

[22] S. A. Sande, Photostability of Drugs and Drug Formulations, H. H. Tonnesen (ed.), Taylor and Francis, London 1996, pp. 323-339.

[23] B. W. Muller and E. Albers, Int. J. Pharm. 79 (1992), 273.

[24] B. N. Rao, M. S. Symala, N. J. Turro, and V. Ramamurthy, J. Org. Chem. 52 (1987), 5517. 


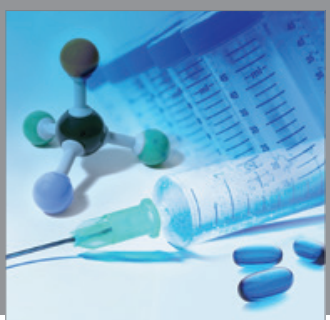

International Journal of

Medicinal Chemistry

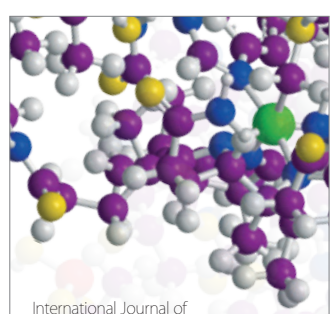

Carbohydrate Chemistry

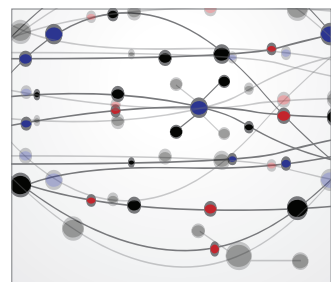

The Scientific World Journal
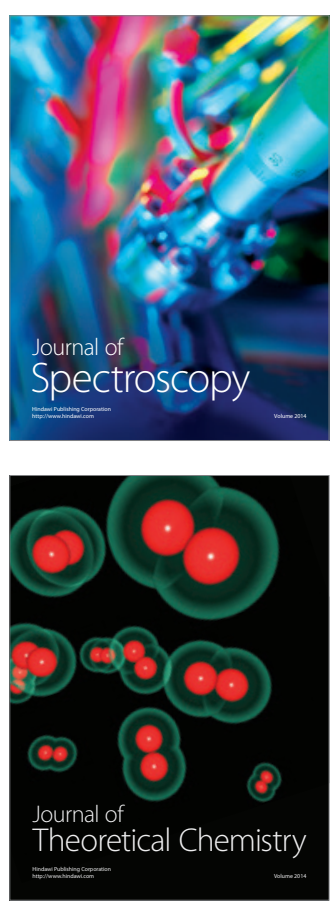
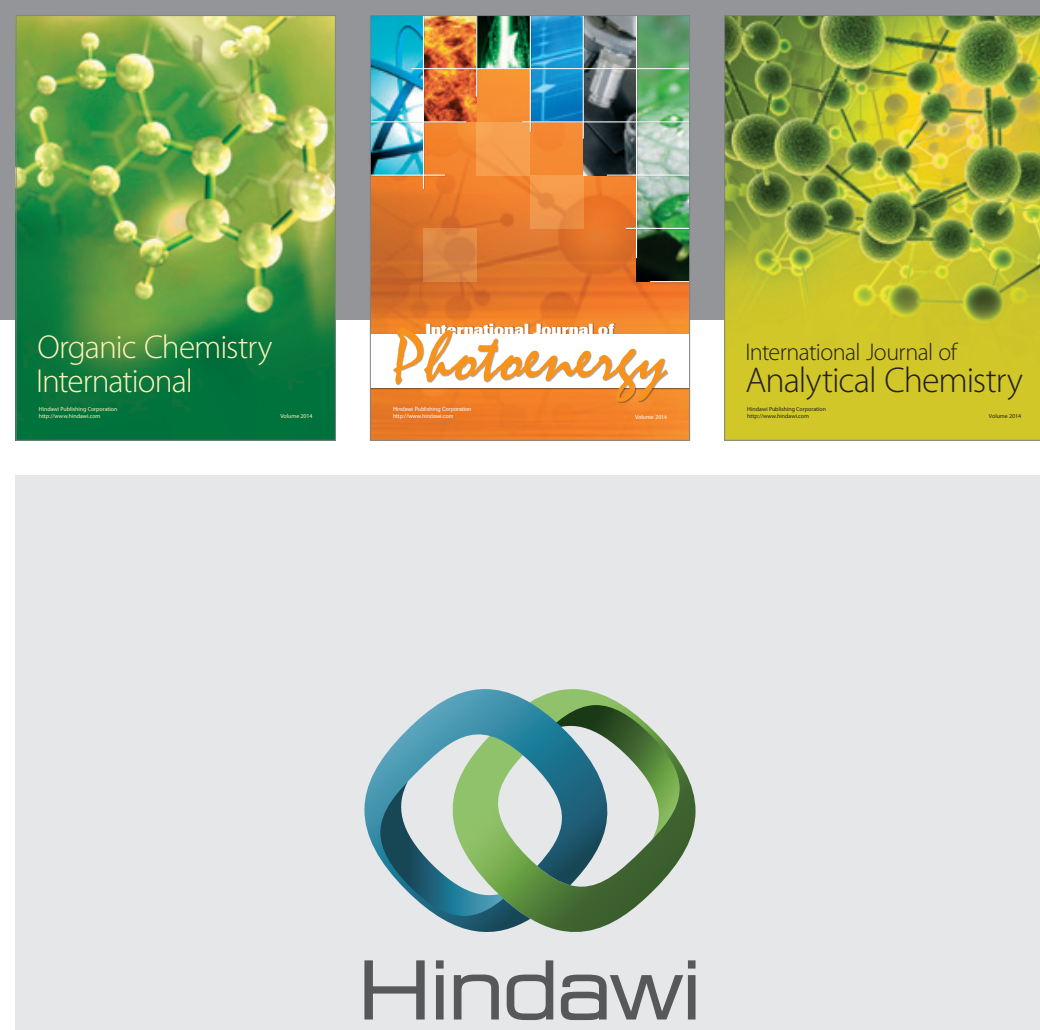

Submit your manuscripts at

http://www.hindawi.com
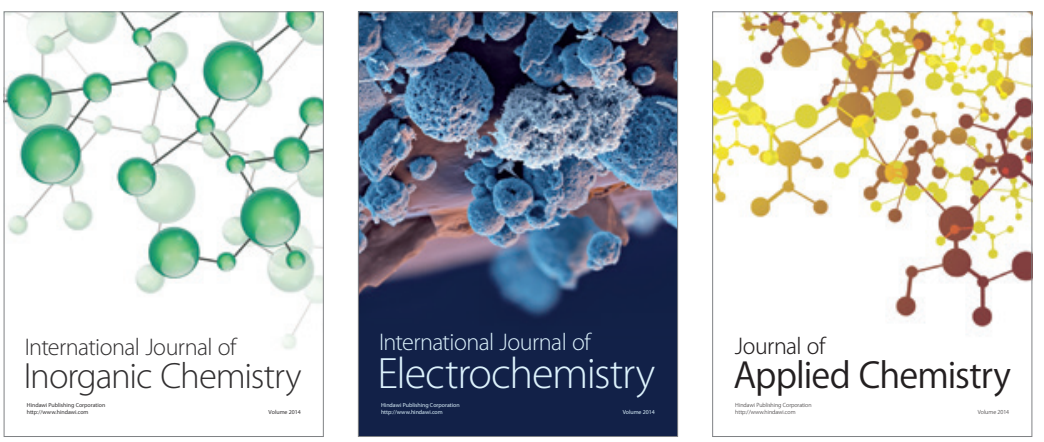

Journal of

Applied Chemistry
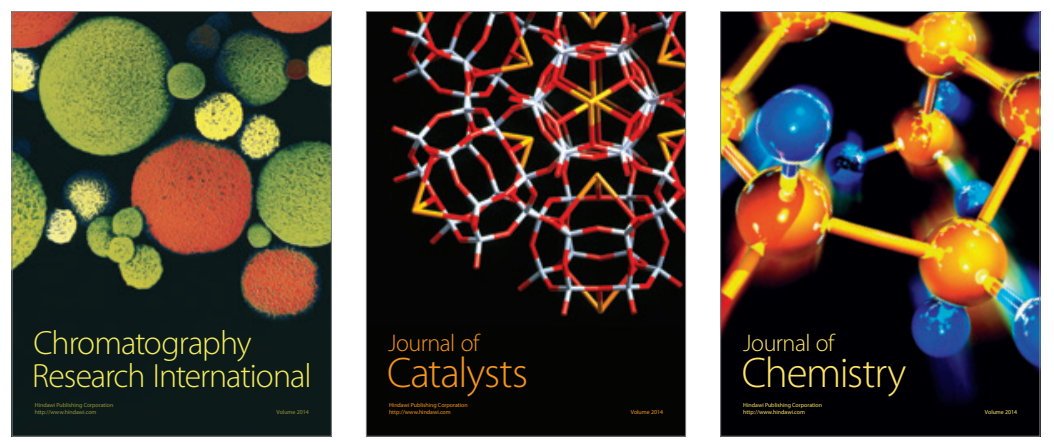
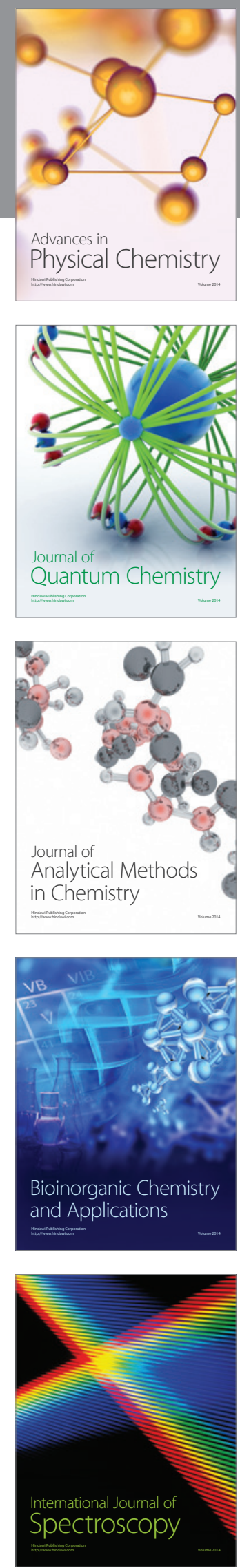